\title{
GaAs pHEMT Cascode Low Noise Amplifier for Wireless Applications
}

\author{
Arjuna Marzuki ${ }^{1}$, Norhapizin $\mathrm{K}^{2}$, Amiza Rasmi ${ }^{2}$, Mohd Azmi Ismail ${ }^{2,}$ Rasidah Sanusi ${ }^{2}$, Ahmad Ismat \\ Abdul Rahim ${ }^{2}$, Mohamed Razman Yahya ${ }^{2}$, Abdul Fatah Awang Mat ${ }^{2}$, Zaliman Sauli ${ }^{3}$, Ali Yeon Md \\ Shakaff ${ }^{3}$
}

\begin{abstract}
This paper presents low noise amplifier (LNA) for wireless application which has been implemented in a $0.15 \mu \mathrm{m}$ GaAs pHEMT technology. The LNA was designed using cascode topology with feedback techniques which produces better gain and good stability over entire frequency. At $2.4 \mathrm{GHz}$, this amplifier achieves power gain of $23 \mathrm{~dB}$, isolation of $35 \mathrm{~dB}$ and input reflection coefficient of $-12 \mathrm{~dB}$ at $2.4 \mathrm{GHz}$. With operating voltage supply at $3 \mathrm{~V}$, the total current consumptions for the LNA is $18 \mathrm{~mA}$
\end{abstract}

\section{INTRODUCTION}

Nowadays, there have been many extensive studies and efforts to improve the noise figure in RF transceivers. The low noise performance which is crucial for the RF Front-End makes Low Noise Amplifier (LNA) plays an important role in $\mathrm{RF}$ transceiver.

It is often for designing a multi-band, multi-mode IC, reconfigurable reference platform design approach is employed [1]. Several RF front-ends in parallel, each dedicated to a single standard, are usually adopted [1]. Broadband topologies have been proposed to process signals belonging to different standards [2], [3]. The main disadvantages of this approach is stringent linearity requirement

Basically, applying shunt feedback to a common source amplifier as shown in Fig. 1 (a) is a good basic building block for broadband amplifier. This technique allows the amplifier to be matched over a broad bandwidth while having minimal impact on the noise figure of the stage [4].

Referring to Fig. 1 (a), the resistor forms the feedback and the capacitor is added to allow for independent biasing of the gate and drain of the transistor. The capacitor can normally be chosen so that it is large enough to be a short circuit over the frequency of interest. This topology offers inferior isolation between output and input.

Fig. 1 (b) shows a cascode topology; here the cascode transistor $\mathrm{M} 2$ provides high impedance which isolates $\mathrm{C}_{\mathrm{GD}}$ of transistor M1 from the output. This cascode transistor provides some isolation between input and output that can increase the stability [5].

In this work, the combination of circuits in Fig. 1(a) and (b) is proposed for LNAs. The work is focused on developing these circuits as core circuit and consequently LNA for 2.4

1School of Electrical and Electronic Engineering,

2Universiti Sains Malaysia, Seri Ampangan, 14300 Nibong Tebal, Penang, Malaysia.

3Telekom Research \& Development Sdn Bhd, Malaysia School of Microelectronic Engineering, Universiti Malaysia Perlis
$\mathrm{GHz}$ and 5.5 GHz application.
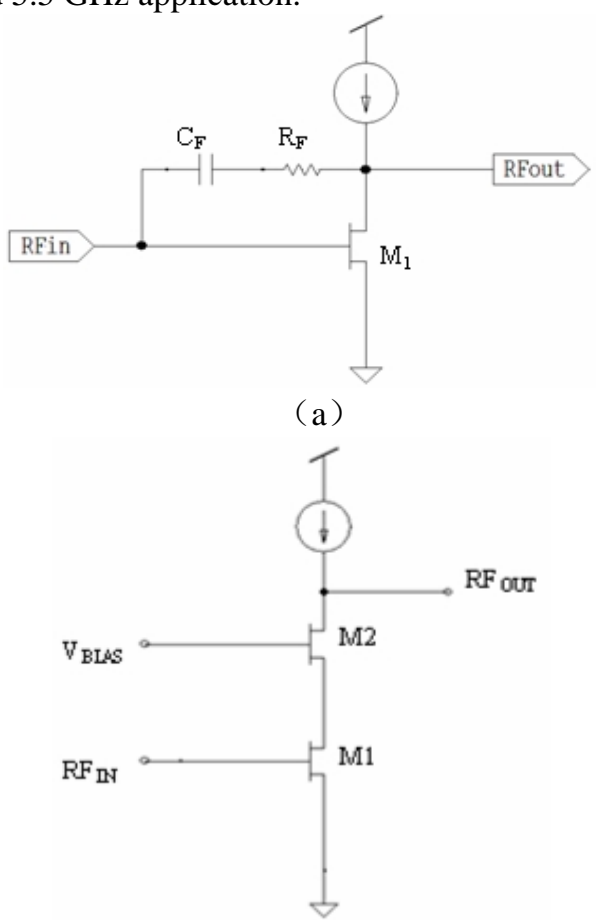

(b)

Fig. 1 (a). Common Source Amplifier with Shunt Feedback (b) Cascode Topology

\section{LNA CIRCUIT DESIGN}

\section{A. Core Circuit}

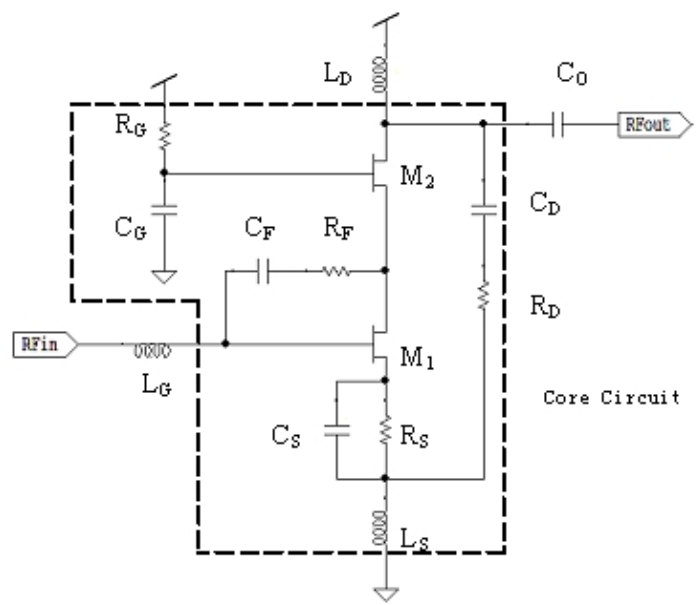

Fig.2. LNA Topology

Fig. 2 shows the schematic of the LNA. $\mathrm{C}_{\mathrm{O}}, \mathrm{L}_{\mathrm{G}}$ and $\mathrm{L}_{\mathrm{D}}$ are matching components for LNA while the core circuit is 
within the dashed box. $\mathrm{M}_{1}$ and $\mathrm{M}_{2}$ are depletion mode devices, $\mathrm{R}_{\mathrm{S}}$ is used to set voltage condition at $\mathrm{M}_{1}$ gate. $\mathrm{C}_{\mathrm{S}}$ is used to short $\mathrm{R}_{\mathrm{S}}$ at interested frequencies. $\mathrm{R}_{\mathrm{G}}$ is used to provide voltage to $\mathrm{M}_{2}$ while $\mathrm{C}_{\mathrm{G}}$ is used to eliminate any noise from the bias network. $L_{S}$ is used for stability. $C_{D}$ and $R_{D}$ is used to further stabilize the LNA core circuit.



Fig. 3. Mu_load and Mu_source vs. Frequency

Fig. 3 shows the mu_load and mu_source parameters which indicate stability of the core circuit. From Fig. 3, it is obvious that the stability network of $C_{D}$ and $R_{D}$ is required to ensure unconditional stable for core circuit for frequency from $1 \mathrm{GHz}$ to $10 \mathrm{GHz}$.

Fig. 4 shows core circuit of LNA, the test chip is measured and modeled for LNAs design.

\section{B. LNA Design}

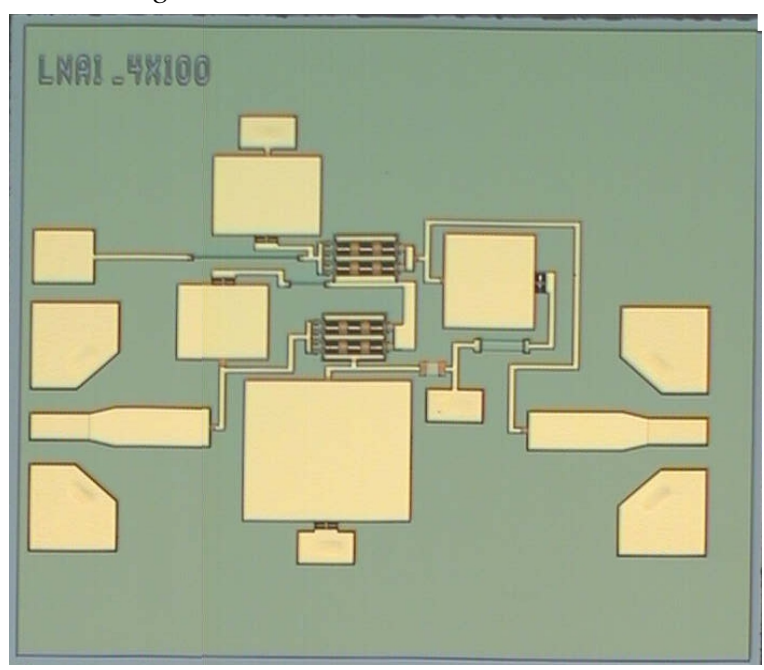

Fig. 4. Core Circuit ( Without LS)

For LNAs design, the transistor $\mathrm{M}_{1}$ and $\mathrm{M}_{2}$ are Depletion-Mode pHEMT and have a gate width of $100 \mu \mathrm{m}$ and 4 fingers. Transistor M1 and M2 is biased at $0 \mathrm{~V}$ and $1 \mathrm{~V}$ respectively. In addition, all the components include inductors are on-chip passive components. Table I shows the simulation results and components value for $2.4 \mathrm{GHz}$ and 5.5 $\mathrm{GHz}$

The $C_{F}$ and $R_{F}$ forms a feedback network for $M_{1}$. The feedback offer easy input matching for the LNA. It does degrade noise while improve the linearity. A simple and intuitive gain equation of LNA,

$$
A_{V}=\frac{R F_{\text {OUT }}}{R F_{I N}}=\frac{g_{m c s} Z_{L}}{1+\frac{Z_{L}}{r_{o c s}}+s C_{m 2-g d} Z_{L}} \text { (1) }
$$

$g_{m c s}$ is transconductance of $\mathrm{M}_{1}$ with feedback network, $Z_{L}$ is load impedance of the LNA, $r_{o c s}$ is output impedance of the $\mathrm{M}_{1}$ with feedback network. Obviously, $\mathrm{R}_{\mathrm{F}}$ which forms the feedback network will affect the gain of the LNA. From Equation (1), the miller effect due to parasitic capacitance of M1 is eliminated.

\section{EXPERIMENTAL RESULTS}

A fully integrated $2.4 \mathrm{GHz}$ LNA in a $0.15 \mu \mathrm{m}$ pHEMT with spiral inductor has been designed and fabricated. As shown in Fig. 5, the LNA employ round inductors for matching components and MIM capacitor for output matching.

TABLE I LNAS SiMULATION RESULTS AND COMPONENTS VALUE

\begin{tabular}{lcc}
\hline \hline \multicolumn{1}{c}{ Parameter } & $2.4 \mathrm{GHz}$ LNA & $5.5 \mathrm{GHz}$ LNA \\
\hline Gain(dB) & 22.34 & 11 \\
$\mathrm{NF}(\mathrm{dB})$ & 1.5 & 1.6 \\
Input P1dB(dBm) & -18 & -10 \\
$\mathrm{~S}_{11}(\mathrm{~dB})$ & -11.53 & -9.2 \\
$\mathrm{~S}_{22}(\mathrm{~dB})$ & -8 & -8 \\
$\mathrm{~V}_{\mathrm{DD}}(\mathrm{V})$ & 3 & 3 \\
$\mathrm{I}_{\mathrm{D}}(\mathrm{mA})$ & 18 & 18 \\
$\mathrm{R}_{\mathrm{F}}(\Omega)$ & 1500 & 1500 \\
$\mathrm{C}_{\mathrm{F}}(\mathrm{pF})$ & 8 & 8 \\
$\mathrm{R}_{\mathrm{S}}(\Omega)$ & 50 & 50 \\
$\mathrm{C}_{\mathrm{S}}(\mathrm{pF})$ & 33 & 33 \\
$\mathrm{C}_{\mathrm{D}}(\mathrm{pF})$ & 10 & 10 \\
$\mathrm{R}_{\mathrm{D}}(\Omega)$ & 520 & 520 \\
$\mathrm{R}_{\mathrm{G}}(\Omega)$ & 5000 & 5000 \\
$\mathrm{C}_{\mathrm{G}}(\mathrm{pF})$ & 10 & 10 \\
$\mathrm{~L}_{\mathrm{S}}(\mathrm{nH})$ & 0.3 & 0.3 \\
$\mathrm{C}_{\mathrm{O}}(\mathrm{pF})$ & 0.6 & 0.15 \\
$\mathrm{~L}_{\mathrm{D}}(\mathrm{nH})$ & 6.7 & 3.7 \\
$\mathrm{~L}_{\mathrm{G}}(\mathrm{nH})$ & 5.2 & 0.9 \\
& &
\end{tabular}

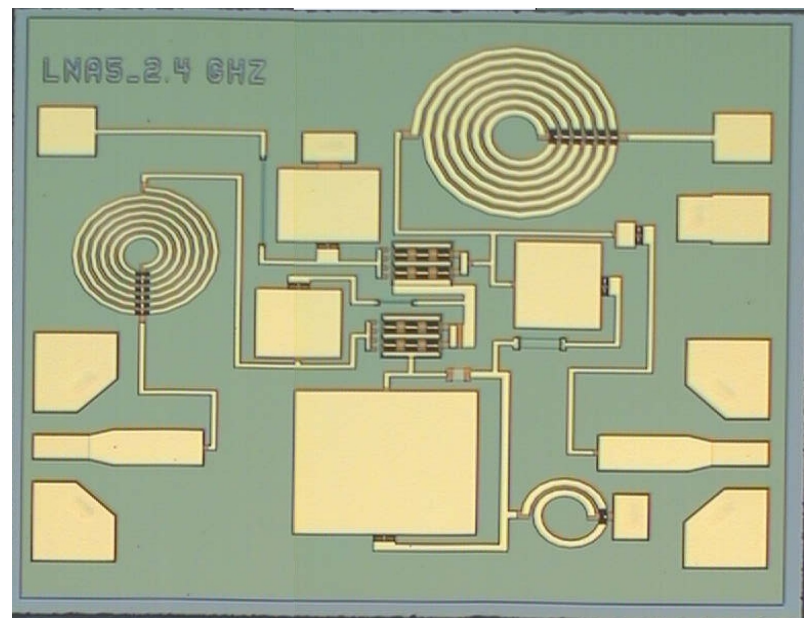

Fig. 5. Die Photo of the $2.4 \mathrm{GHz}$ LNA 


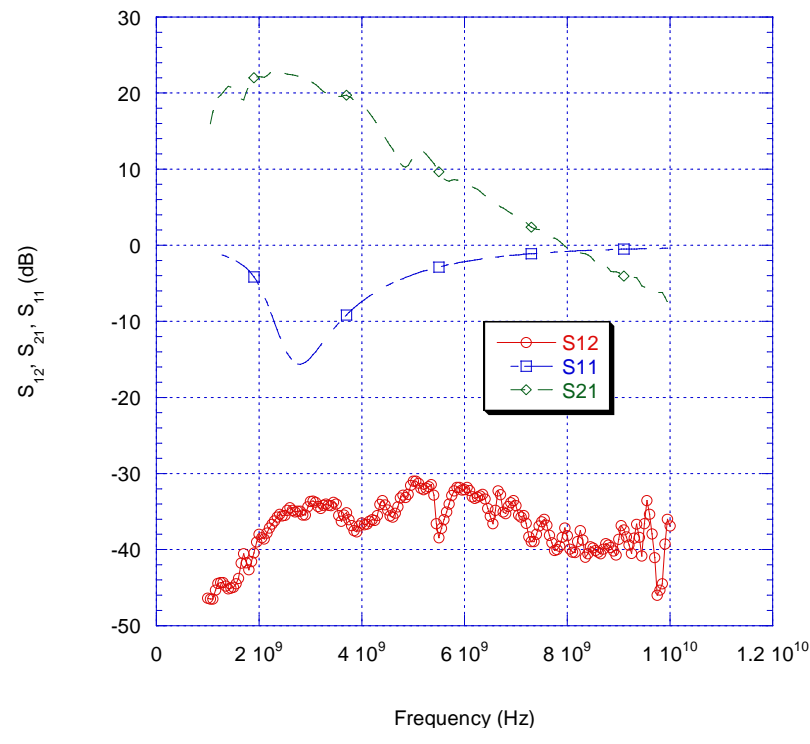

Fig. 6. S-Parameters of LNA

Fig. 6 shows the input reflection coefficient $\left(S_{11}\right)$ of the LNA. The $S_{11}$ is lower than $-10 \mathrm{~dB}$ from $2.3 \mathrm{GHz}$ to $3.5 \mathrm{GHz}$. The measured gain $\left(\mathrm{S}_{21}\right)$ is $23 \mathrm{~dB}$ at $2.4 \mathrm{GHz}$. The isolation $\left(\mathrm{S}_{12}\right)$ is $-35 \mathrm{~dB}$ at $2.4 \mathrm{GHz}$. The LNA is biased with $\mathrm{V}_{\mathrm{DD}}=3 \mathrm{~V}$ and it consumes $18 \mathrm{~mA}$. Noise figure and linearity measurement is in progress.

\section{CONCLUSION}

A Multiband LNA is proposed. A core circuit is designed and used in multiband LNA design. A fully integrated 2.4 $\mathrm{GHz}$ pHEMT LNA with spiral inductor has been designed and tested. The implementation of cascode topology with feedback gives high impact on gain and stability. With the s-parameter result of $\mathrm{S}_{21}$ and $\mathrm{S}_{12}$ is $23 \mathrm{~dB}$ and $-35 \mathrm{~dB}$ respectively, it has been proven that the implemented topology is successful to reduce input-output coupling while producing high gain. Significant stability improvement has been shown by employing stability feedback network which comprises of capacitor and resistor.

\section{ACKNOWLEDGMENT}

The authors gratefully acknowledge the support of TM Research \& Development Sdn. Bhd. for this work under Project number R05-0607-0.

\section{REFERENCES}

[1] Daniel L. Kaczman, Manish Shah, Nihal Godambe, Mohammed Alam, Homero Guimaraes, Lu M. Han, Mohammed Rachedine, David L. Cashen, William E. Getka, Charles Dozier, Wayne P. Shepherd, Karl Couglar, "A single-chip tri-band (2100, 1900, 850/800 MHz) WCDMA/HSDPA cellular transceiver, " IEEE Journal of Solid-State Circuits, vol. 41, pp. 1122 - 1132, May. 2006.

[2] F. Bruccoleri, E. A. M. Klumperink, and B. Nauta, "Wide-band CMOS low-noise amplifier exploiting thermal noise canceling, " IEEE $J$. Solid-State Circuits, vol. 39, no. 2, pp. 275-282, Feb. 2003.

[3] Adiseno, M. Ismail, and H. Olsson, "Awide-band RF front-end for multiband multistandard high-linearity low-IF wireless receivers, " IEEE J.Solid-State Circuits, vol. 37, no. 9, pp. 1162-1168, Sep. 2002.

[4] John Rogers and Calvin Plett, Radio Frequency Integrated Circuit Design : Artech House, Inc., 2003.

[5] Seyed Hossein, Miri Lavasani and Sayfe Kiaei, "A New Method to Stabilize High Frequency High Gain CMOS LNA, " in proceedings of the 2003 10th IEEE International Conference on Electronics, Circuits and System, pp. 982-985.
Arjuna MARZUKI was born in Kedah, Malaysia in 1975. He received B.Eng in electronics from University of Sheffield, UK in 1997 and MSc from Univ. Sains Malaysia in 2004. After graduating with his first degree, he joined Hewlett-Packard as RFIC Design engineer. Currently he is a lecturer in Universiti Sains Malaysia. 